Article

\title{
Long Persistent Luminescent HDPE Composites with Strontium Aluminate and Their Phosphorescence, Thermal, Mechanical, and Rheological Characteristics
}

\author{
Anesh Manjaly Poulose ${ }^{1, *(\mathbb{D})}$, Hamid Shaikh ${ }^{1}$ (D), Arfat Anis ${ }^{1} \mathbb{D}$, Abdullah Alhamidi ${ }^{1}$, Nadavala Siva Kumar ${ }^{2}$, \\ Ahmed Yagoub Elnour ${ }^{2}$ and Saeed M. Al-Zahrani ${ }^{1}$
}

check for updates

Citation: Poulose, A.M.; Shaikh, H.; Anis, A.; Alhamidi, A.; Kumar, N.S.; Elnour, A.Y.; Al-Zahrani, S.M. Long Persistent Luminescent HDPE Composites with Strontium Aluminate and Their Phosphorescence, Thermal, Mechanical, and Rheological Characteristics. Materials 2022, 15, 1142. https://doi.org/10.3390/ ma15031142

Academic Editors: Andrea Petrella and Michele Notarnicola

Received: 16 November 2021

Accepted: 28 January 2022

Published: 1 February 2022

Publisher's Note: MDPI stays neutral with regard to jurisdictional claims in published maps and institutional affiliations.

Copyright: (C) 2022 by the authors. Licensee MDPI, Basel, Switzerland. This article is an open access article distributed under the terms and conditions of the Creative Commons Attribution (CC BY) license (https:// creativecommons.org/licenses/by/ $4.0 /)$.
1 SABIC Polymer Research Center, Department of Chemical Engineering, King Saud University, Riyadh 11421, Saudi Arabia; hamshaikh@ksu.edu.sa (H.S.); aarfat@ksu.edu.sa (A.A.); AKFHK90@hotmail.com (A.A.); szahrani@ksu.edu.sa (S.M.A.-Z.)

2 Department of Chemical Engineering, King Saud University, Riyadh 11421, Saudi Arabia; snadavala@ksu.edu.sa (N.S.K.); aelnour@ksu.edu.sa (A.Y.E.)

* Correspondence: apoulose@ksu.edu.sa

\begin{abstract}
In this work, HDPE/strontium aluminate-based auto glowing composites $\left(\mathrm{SrAl}_{2} \mathrm{O}_{4}: \mathrm{Eu}\right.$, Dy $\left(\mathrm{AG}_{1}\right)$ and $\mathrm{Sr}_{4} \mathrm{Al}_{14} \mathrm{O}_{25}: \mathrm{Eu}$, Dy $\left(\mathrm{AG}_{2}\right)$ ) were prepared, and their phosphorescence studies were conducted. In HDPE / $\mathrm{AG}_{1}$ composites, the green emission was observed at $\sim 500 \mathrm{~nm}$ after the UV excitation at $320 \mathrm{~nm}$. The HDPE $/ \mathrm{AG}_{2}$ has a blue emission at $490 \mathrm{~nm}$ and, in both cases, the intensity of emission is proportional to the $\mathrm{AG}_{1}$ and $\mathrm{AG}_{2}$ content. The DSC data show that the total crystallinity of both the composites was decreased but with a more decreasing effect with the bulky $\mathrm{AG}_{2}$ filler. The melting and crystallization temperatures were intact, which shows the absence of any chemical modification during high shear and temperature processing. This observation is further supported by the ATR-FTIR studies where no new peaks appeared or disappeared from the HDPE peaks. The tensile strength and modulus of HDPE, HDPE/ $\mathrm{AG}_{1}$, and HDPE/ $\mathrm{AG}_{2}$ composites were improved with the $A G_{1}$ and $A G_{2}$ fillers. The rheological studies show the improvement in the complex viscosity and accordingly the storage modulus of the studied phosphorescent HDPE composites. The SEM images indicate better filler dispersion and filler-matrix adhesion, which improves the mechanical characteristics of the studied HDPE composites. The ageing studies in the glowing composites show that there is a decrease in the intensity of phosphorescence emission on exposure to drastic atmospheric conditions for a longer period and the composites become more brittle.
\end{abstract}

Keywords: phosphorescent composites; thermal; mechanical; rheology

\section{Introduction}

The known history of persistent luminescence started at the beginning of the 17th century. In 1602, an Italian shoemaker, V. Casciarolo, observed a solid luminescence from the barite $\left(\mathrm{BaSO}_{4}\right)$, a mineral known as the Bologna stone. The cause for the luminescent emission was unclear, but it was employed for many applications [1]. In the 20th century, the luminous paints were based on the luminescent emission from $\mathrm{Cu}$ - or Mn-doped zinc sulfide (green emission). Their application was later restrained by their shorter afterglow time ( $\sim 30 \mathrm{~min}$.) and lower brightness. These sulfide phosphors have an affinity towards moisture and $\mathrm{CO}_{2}$ and are chemically unstable [2]. The researchers were in search of phosphorescent material that releases visible light for a longer period even after the excitation source (UV, X-ray, etc.) has been stopped. The detection of strontium aluminatebased rare-earth-doped phosphors initiated the modern luminescent materials era. When compared with sulfide phosphors, these phosphors (e.g., SrAlxOy: Eu, Dy) exhibited better afterglow, brightness, chemical stability, environmental safety, and photo-resistance [3]. These materials gain solar light energy, remain photo-luminescent for a longer time $(\sim 16 \mathrm{~h})$, 
and find applications in roadway displays at night-time, glowing paints, fluorescent lamps, pavements, etc. [4-10]. The application side of rare earth metals doped alkaline-earth metals is rapidly expanding due to the faster growth in the nanotechnology field. Due to its long persistent nature and stability, it has also been utilized in areas such as medical imaging and fluorescent probes [11,12].

After the invention of long-lasting $\mathrm{SrAl}_{2} \mathrm{O}_{4}: \mathrm{Eu}^{2+}, \mathrm{Dy}^{3+}$ phosphor in 1996, only a limited number of phosphors were developed to date, which is suitable for practical applications. In recent years, different phases of rare-earth-doped $\left(\mathrm{Pr}^{3+}, \mathrm{Ce}^{3+}, \mathrm{Sm}^{2+}, \mathrm{Nd}^{3+}\right.$, etc. $)$ aluminates were developed, and their emission wavelength depends upon the crystalline structure of the alkaline earth metal aluminate phase [13-18]. Among these phosphors, $\mathrm{SrAl}_{2} \mathrm{O}_{4}$ : $\mathrm{Eu}$, Dy and $\mathrm{Sr}_{4} \mathrm{Al}_{14} \mathrm{O}_{25}$ : Eu, Dy have displayed a robust potential for phosphorescence applications and are available commercially $[19,20]$. These materials undergo hydrolysis in the presence of atmospheric moisture, and the encapsulation process is important to extend the glowing property and is reported in the literature [21-25]. Out of these methods, polymeric encapsulation attracts more due to its low cost, and the process enables the composites to be shaped easily and imparts better physical properties [26-29]. In recent years, research on polymer-phosphor material, composites have gained much attention due to their wide range of potential applications such as safety indication, emergency lighting, road signs, interior decorations, photovoltaics, and optoelectronics [30-32]. In one study, a facile way to synthesize a luminescent polymer nanocomposite of $\mathrm{PMMA}^{-}\left(\mathrm{Sr}_{3} \mathrm{~B}_{2} \mathrm{O}_{6}\right.$ :Dy $\left.{ }^{3}\right)$ is presented, and detailed structural, optical, and photoluminescence properties were investigated. The nanocomposites films consisting of $\left(\mathrm{Sr}_{3} \mathrm{~B}_{2} \mathrm{O}_{6}: \mathrm{Dy}^{3}\right)$ dispersed in polymethyl methacrylate (PMMA) matrix were prepared via solution casting method [31]. In another study, the effect of incorporating different volume loadings (ratios ranging from $0.05 \%$ to $5 \%$ ) of the green-emitting $\mathrm{SrAl}_{2} \mathrm{O}_{4}$ phosphor into both the low-density polyethylene (LDPE) matrix and the (PMMA) matrix was investigated. The composites were produced by the melt-mixing process, and the results showed that LDPE can be used to build a suitable three-dimensional phosphor network for luminescence applications [33]. In recent studies, the incorporation of $\mathrm{SrAl}_{2} \mathrm{O}_{4}: \mathrm{Eu}^{2+}$, $\mathrm{Dy}^{3+}$ powder into polylactic acid (PLA) matrix, as an example of biodegradable polymers with good thermo-plasticity and machinability, was investigated. The results showed that the concentration of $\mathrm{SrAl}_{2} \mathrm{O}_{4}: \mathrm{Eu}^{2+}, \mathrm{Dy}^{3+}$ significantly impacts the fluorescence and mechanical properties of resulting composites and that the composites with $15 \mathrm{wt} . \%$ have the best fluorescence properties [34]. Furthermore, the modification of the $\mathrm{SrAl}_{2} \mathrm{O}_{4}: \mathrm{Eu}^{2+}, \mathrm{Dy}^{3+}$ powder with $\mathrm{SiO}_{2}$ has brought about an improved filler dispersion and compatibility with the (PLA) matrix for 3D printing technologies [26].

Due to its excellent mechanical properties and ease of manufacturing, high-density polyethylene (HDPE) is recognized as one of the most versatile commodity thermoplastics, and it finds a wide acceptance in many industrial applications. The unique properties of HDPE combined with the attractive luminescent features will widen the window of its application in several other interesting areas such as nighttime display boards, sensing, etc. Furthermore, in these reported works the phosphorescence ageing studies exposing the luminescence film to drastic outside temperature conditions are missing. Therefore, in this work, two different strontium aluminate-based phosphorescent materials were melt-mixed with HDPE matrix, and adding to their luminescence, thermal, mechanical, rheological, and morphological studies, the phosphorescence ageing studies were also conducted. The solution casting method makes use of strong solvents, which will inversely affect the mechanical properties of the resultant composites and hence the melt-mixing process is preferred in the present study.

\section{Materials and Methods}

\subsection{Materials}

High-density polyethylene (TASNEE HD F0455) was supplied by TASNEE, Jubail Industrial City, Saudi Arabia, having a density of $0.957 \mathrm{~g} / \mathrm{cm}^{3}$ (ISO 1183). It has a melt flow in$\operatorname{dex}\left(190{ }^{\circ} \mathrm{C} / 5 \mathrm{~kg}\right)$ of $0.40 \mathrm{~g} / 10 \mathrm{~min}$. (ISO 1133). Two strontium aluminate-based phosphors 
$\left(\mathrm{SrAl}_{2} \mathrm{O}_{4}: \mathrm{Eu}\right.$, Dy $(\mathrm{Mw}=209.11 \mathrm{~g} / \mathrm{mol})\left(\mathrm{AG}_{1}\right)$ and $\mathrm{Sr}_{4} \mathrm{Al}_{14} \mathrm{O}_{25}: \mathrm{Eu}$, Dy $(1139.55 \mathrm{~g} / \mathrm{mol})$ $\left(\mathrm{AG}_{2}\right)$, were bought from Sigma Aldrich Company, St. Louis, MO, USA.

\subsection{Methods}

\subsubsection{Composites Preparation}

The strontium aluminate phosphors $\mathrm{AG}_{1}$ and $\mathrm{AG}_{2}(1,3,5$, and $10 \mathrm{wt} . \%)$ were meltblended with the HDPE matrix in DSM Xplore micro-compounder, Sittard, Netherlands, at a temperature of $200{ }^{\circ} \mathrm{C}$ at $100 \mathrm{rpm}$ for a mixing time of $3 \mathrm{~min}$. Thin films with an average thickness of $0.5 \mathrm{~mm}$ were prepared with the help of COLLIN Press, Maitenbeth, Germany (100 bar pressure, $200{ }^{\circ} \mathrm{C}$ ), for the phosphorescence measurements. Dumb-bell-shaped tensile testing specimens ASTM, Type1, were prepared with a microinjection molding machine, DSM Xplore, Sittard, Netherlands $\left(12 \mathrm{~cm}^{3}\right)$. The dumb-bell specimens were shaped in a mold maintained at 6 bar pressure and at room temperature.

\subsubsection{Composites Characterization}

The thermal analysis of the samples (DSC) was carried out in Shimadzu DSC-60A, Kyoto, Japan, taking 5-10 mg material in an aluminum pan, and the temperature program was from 30 to $220^{\circ} \mathrm{C}$ at $10{ }^{\circ} \mathrm{C} / \mathrm{min}$ heating and cooling rate with $4 \mathrm{~min}$. holding time in the melt.

The crystallinity percent was obtained as:

$$
X_{c} \%=\frac{\Delta H_{m}}{(1-\Phi) \Delta H_{m}^{\circ}}
$$

where $(\Phi)$ is the weight fraction of filler in the composites, $\left(\Delta H_{m}\right)$ is the enthalpy of melting obtained from the DSC melting peak, and $\left(\Delta H_{m}^{\circ}\right)$ is the theoretical value of $100 \%$ crystalline HDPE, which is $293 \mathrm{~J} / \mathrm{g}$ [35].

The chemical composition of prepared composites was investigated in an Attenuated Total Reflection-Fourier Transform Infrared Spectroscopy (ATR-FTIR), from ThermoScientific, Waltham, MA USA, Nicolet iN10 model with a germanium micro-tip. The FTIR scanning range was between $400-4000 \mathrm{~cm}^{-1}$.

The morphology and dispersion of the filler particles were studied using SEM. A scanning Electron Microscope (SEM), JEOL JSM-6360A, (Tokyo, Japan), at an accelerating voltage of $20 \mathrm{kV}$, was used for these analyses. The samples for SEM examination were cryo-fractured after exposure to liquid nitrogen. The elemental detection was carried out with the help of the attached energy-dispersive X-ray spectroscopy (EDS) facility.

Tensile testing was carried out in a Hounsfield H100 KS (Salfords, UK) universal testing machine at a crosshead speed of $10 \mathrm{~mm} / \mathrm{min}$ according to the ASTM D638 standard testing method, and an average of five tests is reported.

The rheological properties of HDPE/ $\mathrm{AG}_{1}$ and $\mathrm{HDPE} / \mathrm{AG}_{2}$ samples were carried out in a TA instruments, New Castle, DE, USA, ARG2 model, with parallel-plate geometry. The experimental temperature was set at $190^{\circ} \mathrm{C}$ so that the composites were in a melt state, and the gap between the parallel plate was kept at $1000 \mu \mathrm{m}$ for the analysis. The angular frequency sweep tests were performed from 0.01 to $628.3 \mathrm{rad} / \mathrm{s}$ under an oscillation of 3.259 Pa.

Phosphorescence measurements were performed on an Agilent Technologies Fluorescence Spectrophotometer, Santa Clara, CA, USA equipped with a Xe lamp as a source of UV. The wavelength of excitation used was $320 \mathrm{~nm}$, and the emission spectra from these composites were monitored in the visible range.

\subsubsection{Phosphorescence Intensity vs. Time in $\mathrm{HDPE} / \mathrm{AG}_{1}$ and $\mathrm{HDPE} / \mathrm{AG}_{2}$ Composites}

The phosphorescence decay in these composites was carried out in an Agilent Technologies Fluorescence Spectrophotometer with the delay time and gate time as 0.1 and $10,000 \mathrm{~ms}$. The excitation and emission wavelength is chosen were 320 and $490 \mathrm{~nm}$, respectively, and the decay in the intensity of emission was monitored for a period of 1400 s. 


\subsubsection{Effect of Ageing on Phosphorescence and Mechanical Properties}

$\mathrm{HDPE} / 3 \mathrm{AG}_{1}$ composites films and standard dumb-bell specimens were chosen for the ageing studies (tensile and phosphorescence) and were exposed to outside climatic conditions for 40 days (August-September; Riyadh, Saudi Arabia). The measurements of phosphorescence emission intensity and mechanical properties were monitored in a time interval of 10 days. The ageing phenomenon is mainly influenced by the exposed temperature and humidity. The average day and nighttime temperatures for every 10 days were $42.9,43.1,41.6$, and $38.4^{\circ} \mathrm{C}$ and $28.3,27.6,27.6$, and $24.5^{\circ} \mathrm{C}$; respectively. The average humidity value was around $10 \%$ during that period.

\section{Results and Discussion}

\subsection{Particles and Composites SEM Analysis}

The SEM analysis of $A G_{1}$ and $A G_{2}$ powders are shown in Figure $1 A, B$, respectively. While that of HDPE/ $10 \mathrm{AG}_{1}$ and $\mathrm{HDPE} / 10 \mathrm{AG}_{2}$ composites along with the EDS elemental analysis are shown in Figure 1C-E, respectively. From Figure 1A,B, the SEM images of powder samples, it can be seen that both samples have irregular (random) particle shapes with particle sizes ranging between 5 to $150 \mu \mathrm{m}$ approximately.

Though agglomeration is visible on the SEM images in the highest filler loading composites (Figure 1C,D), the dispersion of the filler and the adhesion among fillers and HDPE is good enough to improve the tensile and storage modulus of the studied composites. The EDS analysis is carried out on the particle visible on the SEM images, and the analysis shows the presence of elements such as $\mathrm{Sr}, \mathrm{Al}$, and $\mathrm{O}_{2}$, confirming the composition of the $\mathrm{AG}_{1}$ fillers, as in Figure $1 \mathrm{E}$.

\subsection{DSC and FTIR Data for HDPE/AG 1 and $H D P E / A G_{2}$ Composites}

The DSC results for the HDPE matrix and the composites are shown in Tables 1 and 2. The $A G_{1}$ and $A G_{2}$ filler do not affect the melting temperature of HDPE, showing that the mixing process is purely physical, and this observation is also supported by the ATR-FTIR data. As shown in Figure $2 \mathrm{~A}, \mathrm{~B}$, the HDPE and the composites with $\mathrm{AG}_{1}$ and $\mathrm{AG}_{2}$ have similar FTIR peaks, confirming the absence of any chemical modification of HDPE during the high-temperature mixing process.

Table 1. DSC results on HDPE and HDPE/AG 1 composites.

\begin{tabular}{ccccc}
\hline Material & $\boldsymbol{T}_{\mathbf{c}}\left({ }^{\circ} \mathbf{C}\right)$ & $\boldsymbol{T}_{\mathbf{m}}\left({ }^{\circ} \mathbf{C}\right)$ & $\Delta \boldsymbol{H}_{\mathbf{m}}(\mathbf{J} / \mathbf{g})$ & $\boldsymbol{X}_{\mathbf{c}}(\mathbf{\%})$ \\
\hline HDPE & 111.1 & 134.4 & 190.2 & 64.9 \\
$\mathrm{HDPE} / 1 \mathrm{AG}_{1}$ & 110.4 & 135.0 & 181.4 & 61.9 \\
$\mathrm{HDPE} / 3 \mathrm{AG}_{1}$ & 111.4 & 134.1 & 173.6 & 59.2 \\
$\mathrm{HDPE} / 5 \mathrm{AG}_{1}$ & 110.2 & 134.6 & 172.1 & 58.7 \\
$\mathrm{HDPE} / 10 \mathrm{AG}_{1}$ & 110.0 & 135.0 & 163.1 & 55.7 \\
\hline
\end{tabular}

Table 2. DSC results on HDPE and HDPE/ $\mathrm{AG}_{2}$ composites.

\begin{tabular}{ccccc}
\hline Material & $\boldsymbol{T}_{\mathbf{c}}\left({ }^{\circ} \mathbf{C}\right)$ & $\boldsymbol{T}_{\mathbf{m}}\left({ }^{\circ} \mathbf{C}\right)$ & $\Delta \boldsymbol{H}_{\mathbf{m}}(\mathbf{J} / \mathbf{g})$ & $\boldsymbol{X}_{\mathbf{c}}(\mathbf{\%})$ \\
\hline HDPE & 111.1 & 134.4 & 190.2 & 64.9 \\
$\mathrm{HDPE} / 1 \mathrm{AG}_{2}$ & 111.5 & 134.3 & 174.1 & 59.4 \\
$\mathrm{HDPE} / 3 \mathrm{AG}_{2}$ & 110.1 & 135.4 & 160.4 & 54.7 \\
$\mathrm{HDPE} / 5 \mathrm{AG}_{2}$ & 110.5 & 134.5 & 160.0 & 54.6 \\
$\mathrm{HDPE} / 10 \mathrm{AG}_{2}$ & 110.6 & 134.3 & 154.1 & 52.6 \\
\hline
\end{tabular}



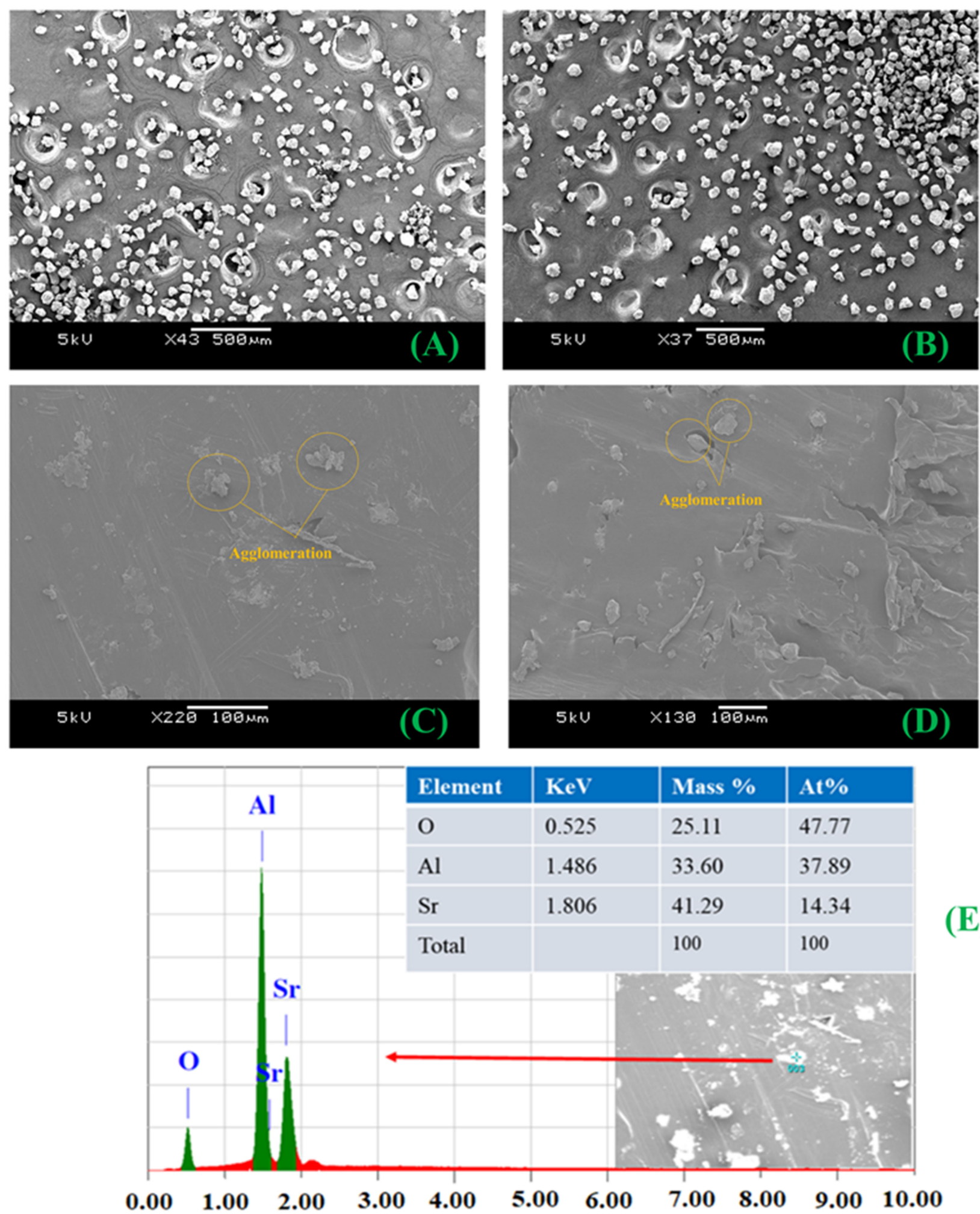

Figure 1. SEM images of $\mathrm{AG}_{1}(\mathbf{A})$ and $\mathrm{AG}_{2}$ (B) powders; and $\mathrm{HDPE} / 10 \mathrm{AG}_{1}(\mathbf{C}), \mathrm{HDPE} / 10 \mathrm{AG}_{2}$ (D), and EDS of HDPE/10AG 1 (E) composites. 

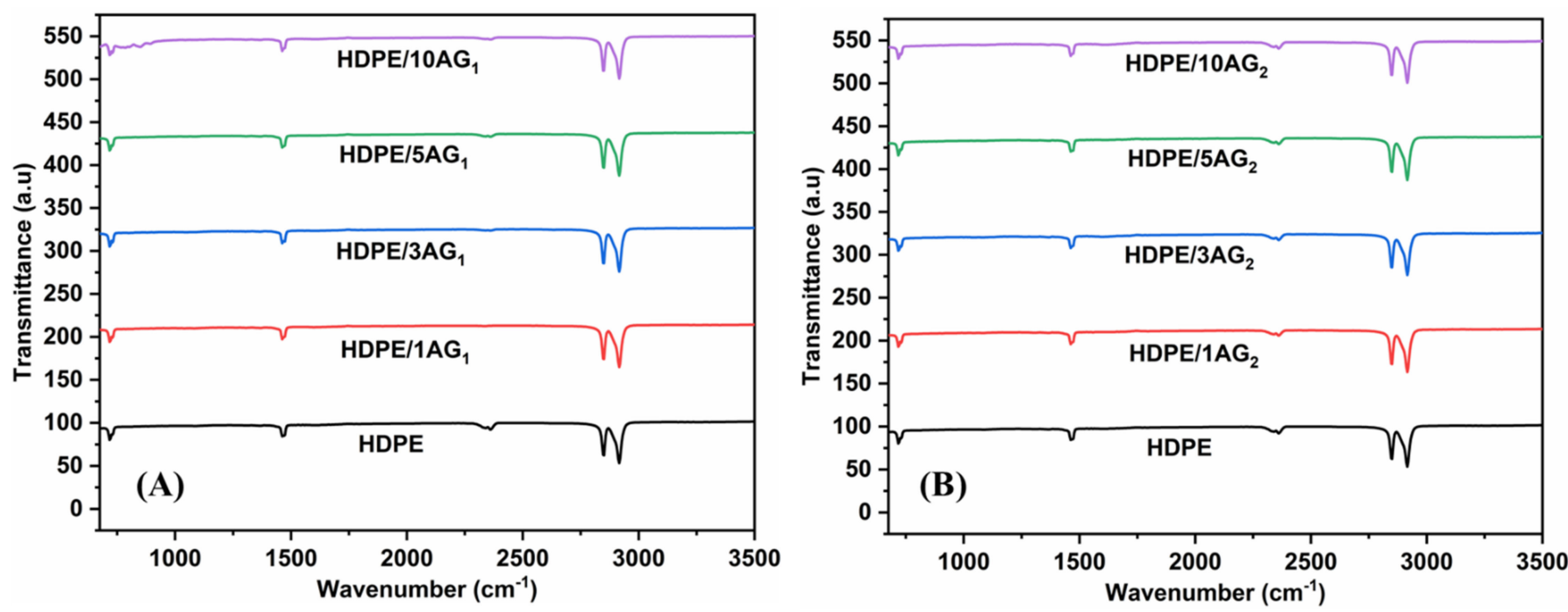

Figure 2. ATR-FTIR data of HDPE and HDPE/AG 1 (A) and HDPE/AG 2 (B) composites.

On the other hand, the $\mathrm{AG}_{1}$ and $\mathrm{AG}_{2}$ fillers have a significant effect on the crystallinity of HDPE, as shown in Tables 1 and 2, with a more pronounced effect on composites with $\mathrm{AG}_{2}$ filler due to the bulky chemical structure of $\mathrm{AG}_{2}$ than $\mathrm{AG}_{1}$ [36].

\subsection{Mechanical Characterization of $H D P E / A G_{1}$ and $H D P E / A G_{2}$}

The mechanical properties of the composites are important for the application side of the auto-glowing composites. The tensile strength and modulus of HDPE, HDPE/AG 1 , and $\mathrm{HDPE} / \mathrm{AG}_{2}$ composites are shown in Figure $3 \mathrm{~A}, \mathrm{~B}$, respectively. It is found that at lower filler loading (1-3 wt.\%), the tensile strength was found to be improved and then decreases on further filler loading due to the agglomeration of the fillers, especially at higher filler loading concentration. The tensile modulus increases from 0.84 to $0.873 \mathrm{GPa}$, increasing the filler content from 0 to $10 \mathrm{wt} . \%$.
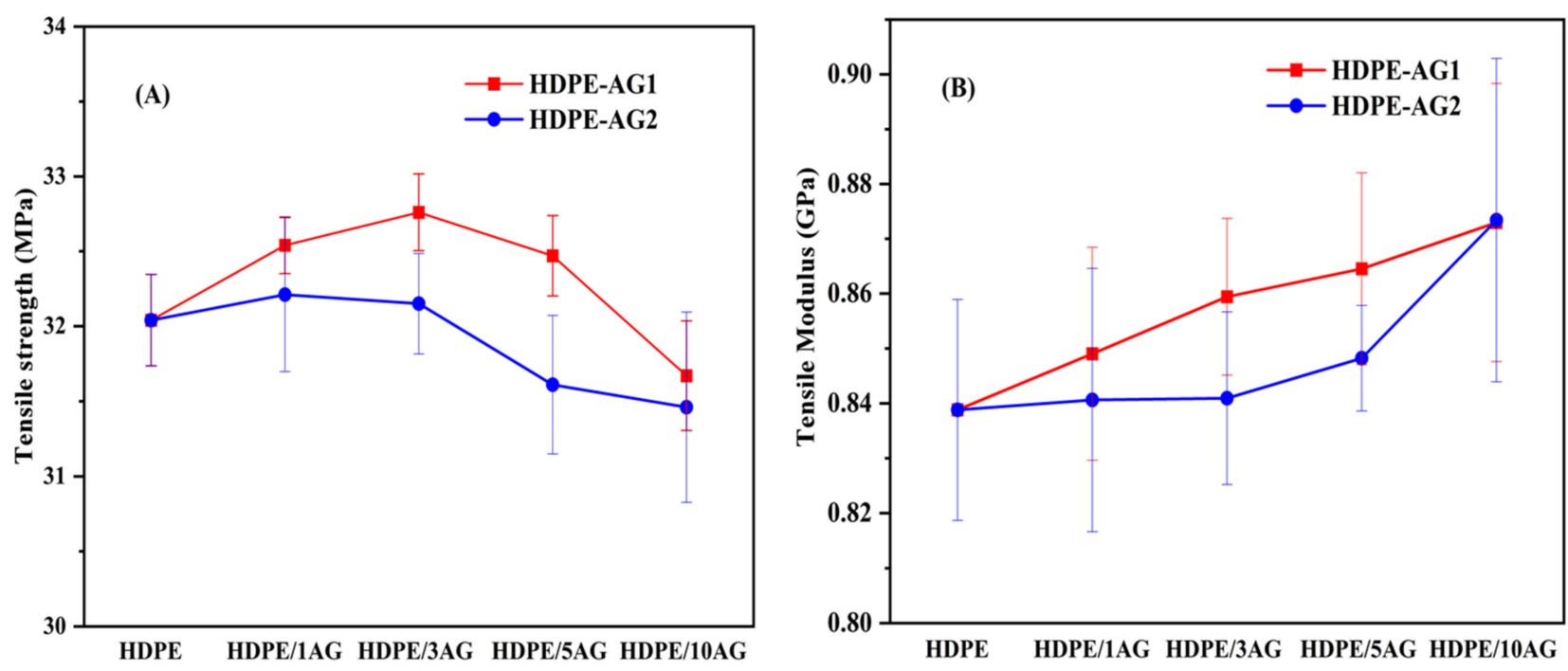

Figure 3. Tensile strength (A) and tensile modulus (B) in HDPE, HDPE/AG 1 , and HDPE/ $\mathrm{AG}_{2}$ composites.

\subsection{Rheological Studies in $H D P E / A G_{1}$ and $H D P E / A G_{2}$ Composites}

The storage modulus and complex viscosity of $\mathrm{HDPE} / \mathrm{AG}_{1}$ and $\mathrm{HDPE} / \mathrm{AG}_{2}$ composites are shown in Figures 4 and 5, respectively. For both composites, the $A_{1}$ and $A_{2}$ fillers have a positive effect on both the complex viscosity and storage moduli of the composites, 
especially at a lower frequency range. The complex viscosity increment shows the good filler-HDPE interaction and improves the storage moduli of the studied composites. As shown in Figure 4, there is a gradual increase in the moduli value of the composites with the $\mathrm{AG}_{1}$ and $\mathrm{AG}_{2}$ content.
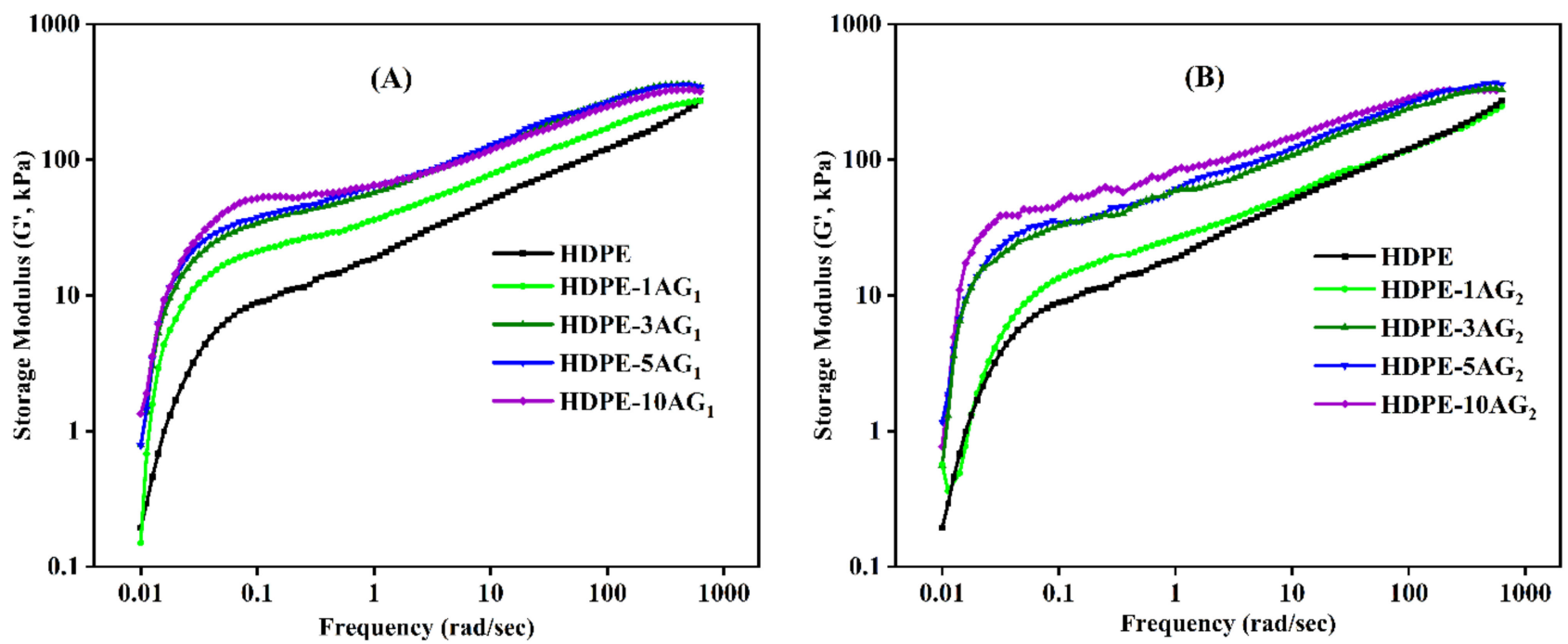

Figure 4. Storage modulus in $\mathrm{HDPE} / \mathrm{AG}_{1}(\mathbf{A})$ and $\mathrm{HDPE} / \mathrm{AG}_{2}(\mathbf{B})$ composites.

A

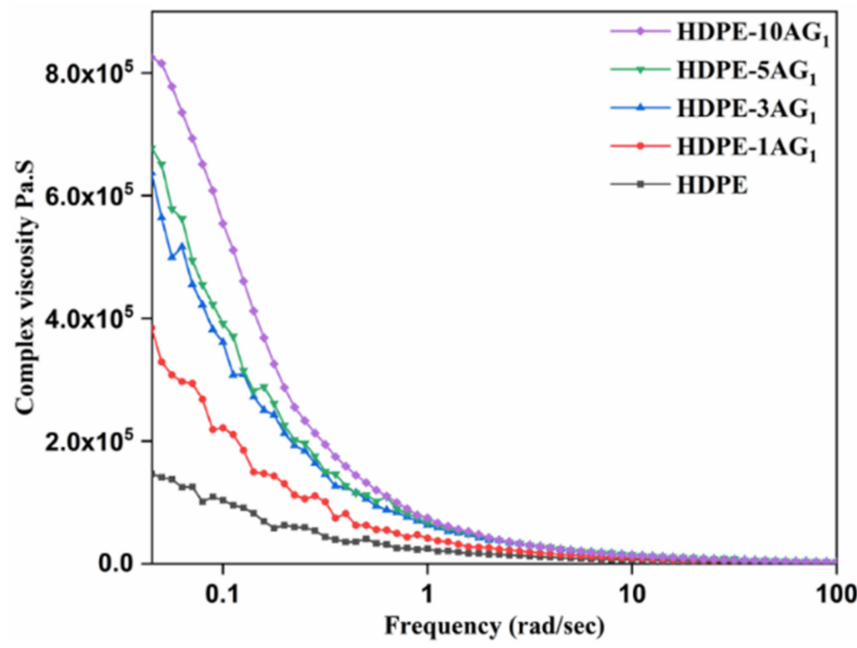

B

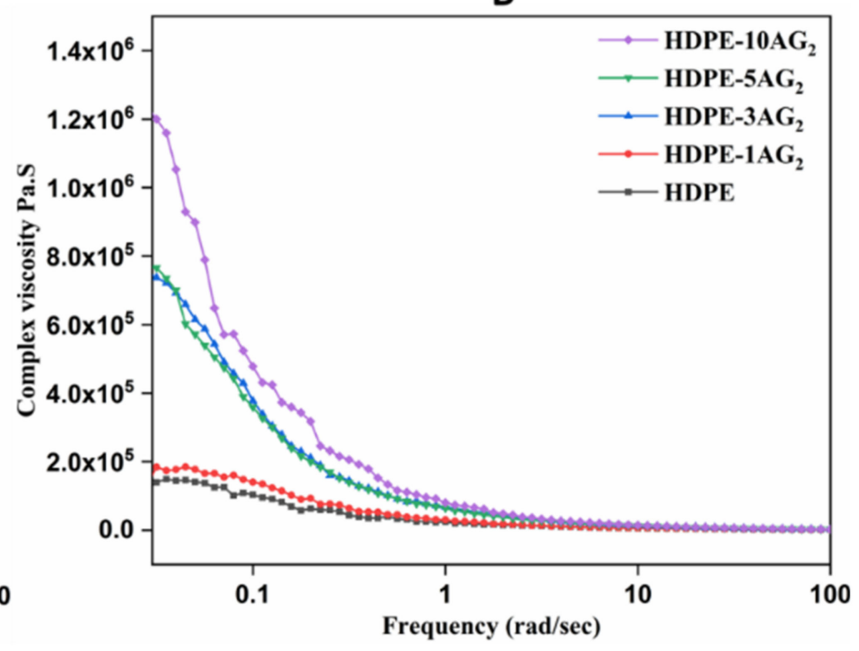

Figure 5. Complex viscosity data in $\mathrm{HDPE} / \mathrm{AG}_{1}(\mathbf{A})$ and $\mathrm{HDPE} / \mathrm{AG}_{2}$ (B) composites.

\subsection{Phosphorescence Studies in $H D P E / A G_{1}$ and $H D P E / A G_{2}$ Composites}

The physical mechanism behind the phosphorescence phenomena is briefly divided into four processes: (i) when the phosphor is excited by external excitation illumination at specific wavelengths takes place upon the liberation of charge carriers (electrons and/or holes); (ii) the excited electrons or generated holes can be non-radiatively acquired by the electron or hole traps through a conduction band (CB) or valence band (VB), respectively, or by the quantum tunneling process through the forbidden band, known as the trapping process. The traps do not emit electromagnetic radiation but they store the excitation energy for a long time (optical battery). (iii) After stopping the excitation, the captured charge carriers can be released mainly by thermal stimulation energy (other stimulations like optical or mechano-ones are out of the scope in this paper), termed a de-trapping process. (iv) Finally, the released charge carriers move back to the emission center, yielding the delayed luminescence due to the electron-hole recombination [37-39]. 
The phosphorescence measurements for $\mathrm{HDPE} / \mathrm{AG}_{1}$ and $\mathrm{HDPE} / \mathrm{AG}_{2}$ are shown in Figure $6 \mathrm{~A}, \mathrm{~B}$, respectively. The UV excitation was carried out at $320 \mathrm{~nm}$, and the intensity of emission was monitored in HDPE composites with $A_{1}$ and $A G_{2}$ fillers. In HDPE/AG composites, green emission was observed at $\sim 500 \mathrm{~nm}$, due to the $4 \mathrm{f}^{6} 5 \mathrm{~d}^{1}$ to $4 \mathrm{f}^{7}$ transition of $\mathrm{Eu}^{+2}$ ion of the $\mathrm{AG}_{1}$ phosphor sample, and, as expected, the intensity of emission was found to increase with the increased loading percentage of the $A_{1}$ phosphor, as shown in Figure 6A. For the HDPE/ $\mathrm{AG}_{2}$, a blue emission at $490 \mathrm{~nm}$ was observed, and similar to the $\mathrm{AG}_{1}$ sample, the emission intensity is proportional to the $\mathrm{AG}_{2}$ content (Figure $6 \mathrm{~B}$ ).
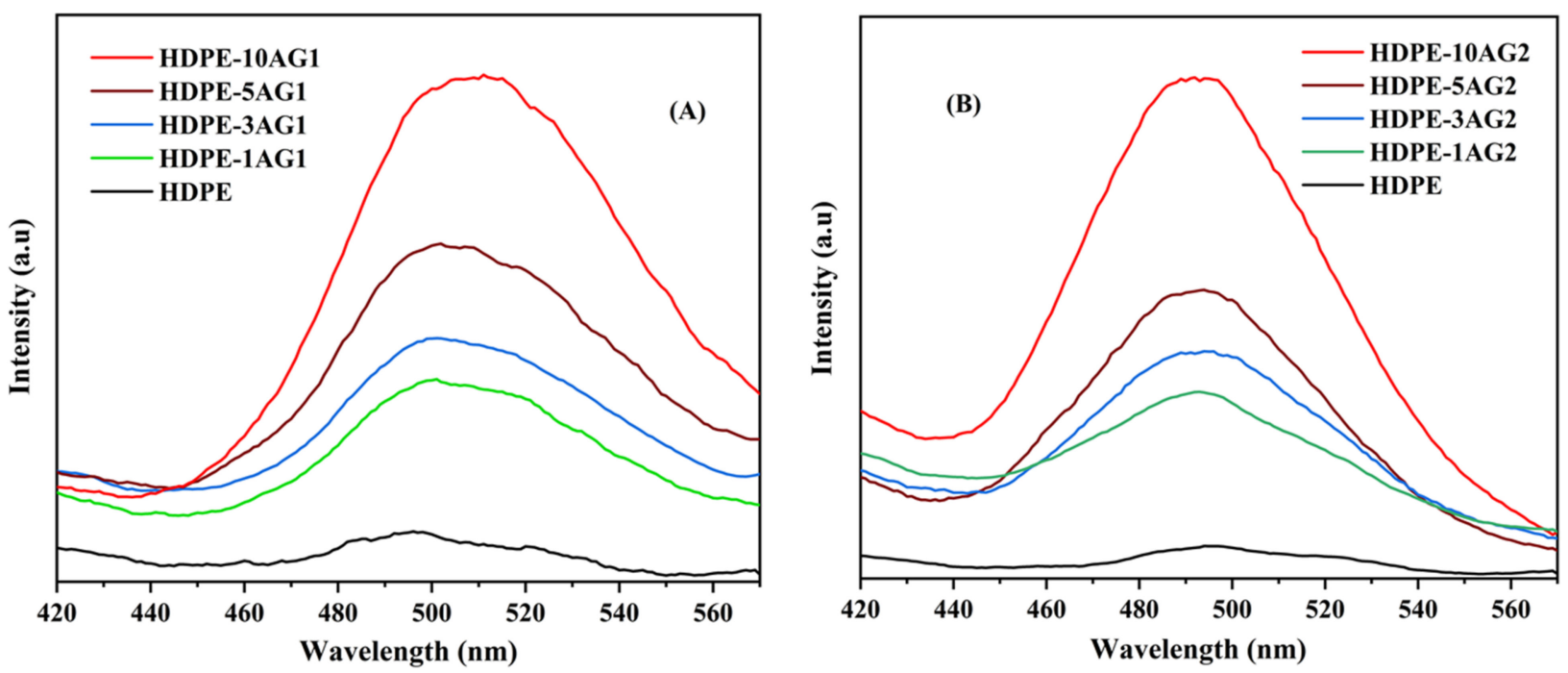

Figure 6. Phosphorescence emission in $\mathrm{HDPE}, \mathrm{HDPE} / \mathrm{AG}_{1}(\mathbf{A})$, and $\mathrm{HDPE} / \mathrm{AG}_{2}$ (B) composites.

The HDPE / $\mathrm{AG}_{1}$ (green) and $\mathrm{HDPE} / \mathrm{AG}_{2}$ (blue) emission under darkness can be visible from Figure 7 , and the intensity of emission is proportional to the filler content $\left(\mathrm{AG}_{1}\right.$ and $\mathrm{AG}_{2}: 1$ to $\left.10 \mathrm{wt} . \%\right)$.

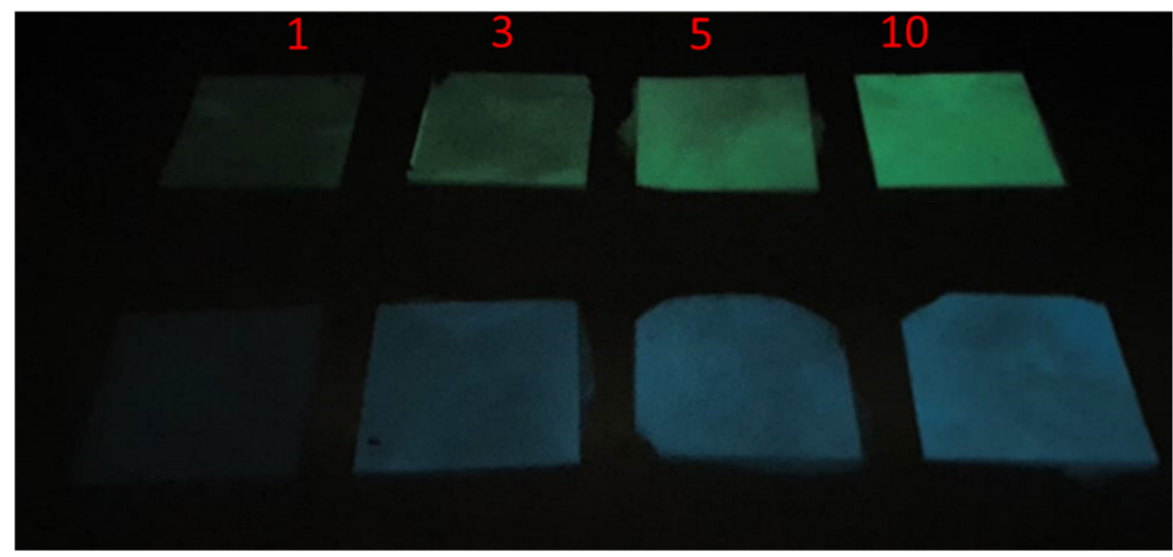

Figure 7. Phosphorescence emission under darkness; green for $\mathrm{AG}_{1}$ composites and blue for $\mathrm{AG}_{2}$ composites (1-10 wt.\%).

\subsection{Phosphorescence Intensity Decay Studies in $H D P E / A G_{1}$ and $H D P E / A G_{2}$ Composites}

The phosphorescence decay for the studied composites is shown in Figure 8. In both composites, the phosphorescence intensity decay rate is inversely proportional to the $\mathrm{AG}_{1}$ and $\mathrm{AG}_{2}$ filler content, i.e., the composites with higher filler content decay slowly. One can see that, with the 10 and 5 wt. $\% A_{1}$ and $A_{2}$ composites, the decay rate is very slow and the final intensity is not reaching a zero value as previously reported for similar materials [34,40]. The afterglow for these materials is considerably higher; therefore, no such behavior was observed within the studied timespan. 

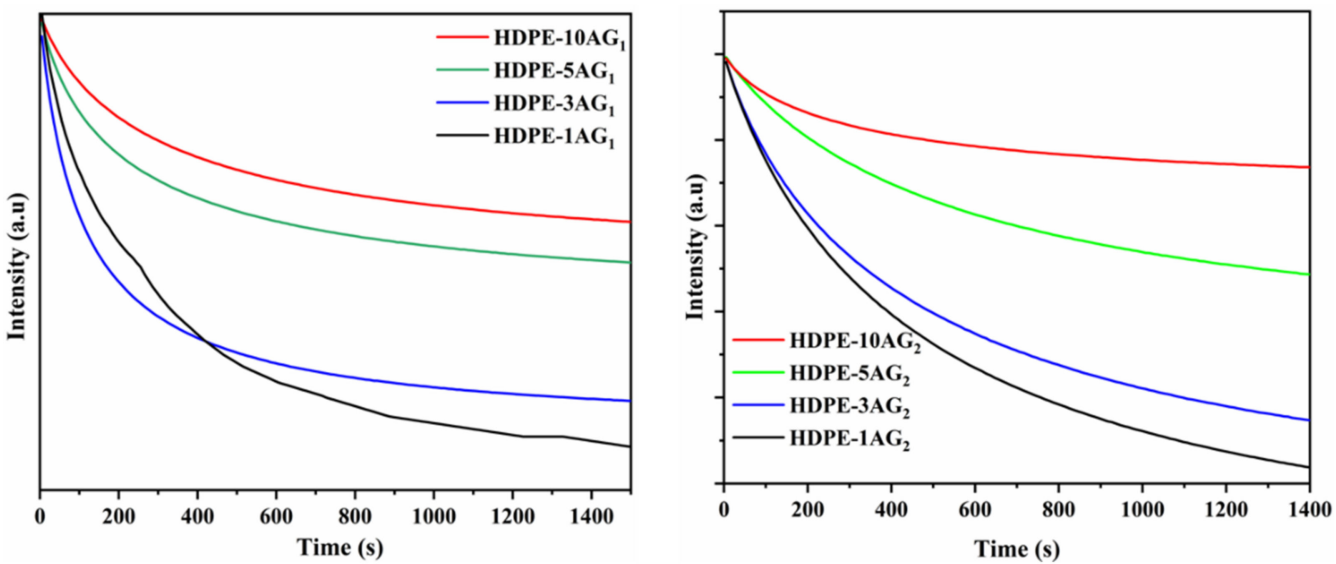

Figure 8. Phosphorescence intensity vs. time in $\mathrm{HDPE} / \mathrm{AG}_{1}$ and $\mathrm{HDPE} / \mathrm{AG}_{2}$ composites.

\subsection{Effect of Ageing on Phosphorescence and Mechanical Properties}

The effect of aging on the phosphorescence and mechanical properties of the composite samples were conducted by the composite films to outside atmospheric conditions, for different exposure times (up to 40 days), and the phosphorescent and mechanical properties measurements were conducted in 10 days. For the sake of brevity, only the HDPE/3AG composite sample was selected. Considering the phosphorescence characteristics of composites, it was found that there is a decrease in the emission intensity due to the ageing phenomena and that this decrease in intensity is directly proportional to the number of exposure days (Figure 9). On the other hand, the effect of aging on tensile strength was found to be negligible, and the tensile modulus values decrease on ageing. It was also observed that both tested samples, neat HDPE and HDPE $/ 3 \mathrm{AG}_{1}$ composite, became more brittle, as evidenced by the reduction in elongation percentages with an increased number of exposure days. The elongation at break for neat HDPE was found to be decreased from 58.5 to 18.82 , while that of HDPE $/ 3 \mathrm{AG}_{1}$ composite was from 48 to 11 (Table 3). This latter observation is due to the physical aging phenomena that takes place for the sample at the outside atmospheric conditions [41].

Table 3. Tensile strength, tensile modulus, and elongation data on HDPE and HDPE/3AG 1 composites on ageing.

\begin{tabular}{cccccc}
\hline Material & $\begin{array}{c}\text { Tensile Strength } \\
\text { MPa }\end{array}$ & SD & $\begin{array}{c}\text { Tensile Modulus } \\
\text { GPa }\end{array}$ & Elongation \% & SD \\
\hline HDPE & 32.04 & 0.31 & 0.84 & 58.5 & 4.58 \\
HDPE-10days & 33.63 & 0.49 & 0.70 & 51.22 & 5.17 \\
HDPE/20days & 34.12 & 1.48 & 0.67 & 39.51 & 6.31 \\
HDPE/30days & 33.51 & 0.20 & 0.66 & 20.28 & 7.5 \\
HDPE/40 days & 32.1 & 0.63 & 0.64 & 18.82 & 3.1 \\
\hline HDPE/3AG & 31.94 & 0.34 & 0.84 & 48.14 & 4.11 \\
HDPE/3AG $/ 10$ days & 34.41 & 0.32 & 0.82 & 40.12 & 3.12 \\
HDPE/3AG $/ 20$ days & 34.12 & 0.51 & 0.79 & 36.32 & 4.2 \\
HDPE/3AG $/ 30$ days & 33.51 & 0.27 & 0.77 & 15.66 & 3.02 \\
HDPE/3AG $/ 40$ days & 33.95 & 0.59 & 0.72 & 11.21 & 2.51 \\
\hline
\end{tabular}




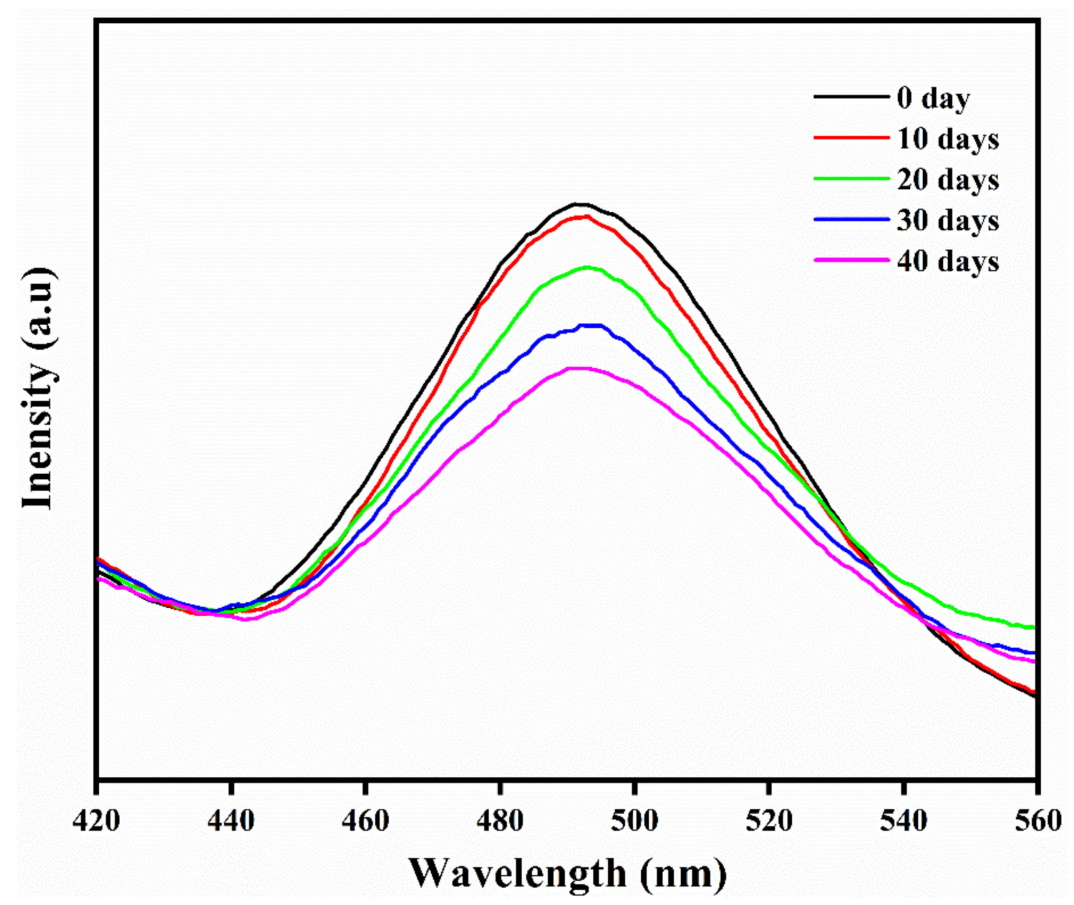

Figure 9. Phosphorescence decay for $\mathrm{HDPE} / 3 \mathrm{AG}_{1}$ composites every 10 days.

\section{Conclusions}

Long afterglow HDPE-based strontium aluminate composites were prepared and characterized for their application side. The HDPE-encapsulated $A_{1}$ and $A G_{2}$ composites resulted in long afterglow composites, which lasted for many hours. The physical mixing was confirmed from both the DSC and ATR-FTIR studies. The green $(\sim 500 \mathrm{~nm})$ and blue emission $(\sim 490 \mathrm{~nm})$ were observed for the $A G_{1}$ and $A G_{2}$ composites, respectively, and the intensity of emission improves with the amount of $A_{1} G_{1}$ and $A G_{2}$ fillers. The DSC data show that the total crystallinity of both the composites was decreased but with a more decreasing effect with the bulky $A_{2}$ filler without affecting the melting and crystallization temperature. The rheological results show the increase in complex viscosity and thereby the storage modulus values in the resulted composites. SEM pictures reveal good dispersion of the fillers in the HDPE matrix, and the tensile strength and modulus were found to be increased with the proportion of the fillers. Due to the better mechanical characteristics and long afterglow time, these composites can be found in applications in roadway nighttime displays, fluorescent lamps, etc. The ageing studies in the glowing composites show that there is a decrease in the intensity of phosphorescence emission on exposure to outside temperature for a longer period, and the composites become more and more brittle on ageing, .

Author Contributions: Conceptualization, A.M.P.; investigation, A.A. (Abdullah Alhamidi) and A.Y.E.; writing—original draft preparation, A.M.P.; writing—review and editing, A.M.P., H.S., N.S.K., and A.A. (Arfat Anis); supervision, A.M.P. and S.M.A.-Z.; project administration, A.M.P. All authors have read and agreed to the published version of the manuscript.

Funding: This project was funded by the National Plan for Science, Technology, and Innovation (MAARIFAH), King Abdulaziz City for Science and Technology, Kingdom of Saudi Arabia, Award Number (13-ADV1044-02).

Institutional Review Board Statement: Not applicable.

Informed Consent Statement: Not Applicable.

Data Availability Statement: The data presented in this study are available on request from the corresponding author. 
Acknowledgments: This project was funded by the National Plan for Science, Technology, and Innovation (MAARIFAH), King Abdulaziz City for Science and Technology, Kingdom of Saudi Arabia, Award Number (13-ADV1044-02).

Conflicts of Interest: The authors declare no conflict of interest.

\section{References}

1. Hölsä, J. Persistent luminescence beats the afterglow: 400 years of persistent luminescence. Electrochem. Soc. Interface 2009, 18, 42. [CrossRef]

2. Harvey, E.N. A History of Luminescence from the Earliest Times until 1900; American Philosophical Society: Philadelphia, PA, USA, 1957; pp. 1-677.

3. Abbruscato, V. Optical and Electrical Properties of $\mathrm{SrAl}_{2} \mathrm{O}_{4}: \mathrm{Eu}^{2+}$. J. Electrochem. Soc. 1971, 118, 930. [CrossRef]

4. Katsumata, T.; Sasajima, K.; Nabae, T.; Komuro, S.; Morikawa, T. Characteristics of strontium aluminate crystals used for long-duration phosphors. J. Am. Ceram. Soc. 1998, 81, 413-416. [CrossRef]

5. Katsumata, T.; Nabae, T.; Sasajima, K.; Komuro, S.; Morikawa, T. Effects of Composition on the Long Phosphorescent SrAl $\mathrm{O}_{4}$ : $\mathrm{Eu}^{2+}, \mathrm{Dy}^{3+}$ Phosphor Crystals. J. Electrochem. Soc. 1997, 144, L243. [CrossRef]

6. Nance, J.; Sparks, T.D. From streetlights to phosphors: A review on the visibility of roadway markings. Prog. Org. Coat. 2020, 148, 105749. [CrossRef]

7. Nance, J.; Sparks, T.D. Comparison of coatings for $\mathrm{SrAl}_{2} \mathrm{O}_{4}: \mathrm{Eu}^{2+}, \mathrm{Dy}^{3+}$ powder in waterborne road striping paint under wet conditions. Prog. Org. Coat. 2020, 144, 105637. [CrossRef]

8. Lin, Y.-C.; Karlsson, M.; Bettinelli, M. Inorganic phosphor materials for lighting. Top. Curr. Chem. 2016, 374, 21. [CrossRef]

9. Tan, H.; Wang, T.; Shao, Y.; Yu, C.; Hu, L. Crucial breakthrough of functional persistent luminescence materials for biomedical and information technological applications. Front. Chem. 2019, 7, 387. [CrossRef]

10. Wang, W.; Sha, A.; Lu, Z.; Yuan, D.; Jiang, W.; Liu, Z. Cement filled with phosphorescent materials for pavement: Afterglow decay mechanism and properties. Constr. Build. Mater. 2021, 284, 122798. [CrossRef]

11. Maldiney, T.; Richard, C.; Seguin, J.; Wattier, N.; Bessodes, M.; Scherman, D. Effect of Core Diameter, Surface Coating, and PEG Chain Length on the Biodistribution of Persistent Luminescence Nanoparticles in Mice. ACS Nano 2011, 5, 854-862. [CrossRef]

12. Paterson, A.S.; Raja, B.; Garvey, G.; Kolhatkar, A.; Hagström, A.E.; Kourentzi, K.; Lee, T.R.; Willson, R.C. Persistent luminescence strontium aluminate nanoparticles as reporters in lateral flow assays. Anal. Chem. 2014, 86, 9481-9488. [CrossRef]

13. Chen, W.; Wang, Y.; Zeng, W.; Han, S.; Li, G.; Guo, H.; Li, Y.; Qiang, Q. Long persistent composite phosphor $\mathrm{CaAl}_{2} \mathrm{O}_{4}$ : Eu ${ }^{2+}$, $\mathrm{Nd}^{3+} / \mathrm{Y}_{3} \mathrm{Al}_{5} \mathrm{O}_{12}$ : $\mathrm{Ce}^{3+}$ : A novel strategy to tune the colors of persistent luminescence. New J. Chem. 2016, 40, 485-491. [CrossRef]

14. Zheng, R.; Xu, L.; Qin, W.; Chen, J.; Dong, B.; Zhang, L.; Song, H. Electrospinning preparation and photoluminescence properties of $\mathrm{SrAl}_{2} \mathrm{O}_{4}: \mathrm{Ce}^{3+}$ nanowires. J. Mater. Sci. 2011, 46, 7517-7524. [CrossRef]

15. Sakirzanovas, S.; Katelnikovas, A.; Dutczak, D.; Kareiva, A.; Jüstel, T. Synthesis and $\mathrm{Sm}^{2+} / \mathrm{Sm}^{3+}$ doping effects on photoluminescence properties of $\mathrm{Sr}_{4} \mathrm{Al}_{14} \mathrm{O}_{25}$. J. Lumin. 2011, 131, 2255-2262. [CrossRef]

16. Feng, X.; Feng, W.; Wang, K. Experimental and theoretical spectroscopic study of praseodymium (III) doped strontium aluminate phosphors. J. Alloy. Compd. 2015, 628, 343-346. [CrossRef]

17. Lupei, A.; Lupei, V.; Gheorghe, C.; Gheorghe, L.; Vivien, D.; Aka, G.; Antic-Fidancev, E. Disorder effects in Nd ${ }^{3+}$-doped strontium hexa-aluminate laser crystals. J. Phys. Condens. Matter 2005, 18, 597-611. [CrossRef]

18. Lu, B.; Shi, M.; Pang, Z.; Zhu, Y.; Li, Y. Study on the optical performance of red-emitting phosphor: $\mathrm{SrAl}_{2} \mathrm{O}_{4}$ : $\mathrm{Eu}^{2+}$, $\mathrm{Dy}^{3+} / \mathrm{Sr}_{2} \mathrm{MgSi}_{2} \mathrm{O}_{7}: \mathrm{Eu}^{2+}, \mathrm{Dy}^{3+} /$ light conversion agent for long-lasting luminous fibers. J. Mater. Sci. Mater. Electron. 2021, 1-13. [CrossRef]

19. Sahu, I.P.; Bisen, D.; Sharma, R. UV excited green luminescence of $\mathrm{SrAl}_{2} \mathrm{O}_{4}: \mathrm{Eu}^{2+}, \mathrm{Dy}^{3+}$ nanophosphor. Res. Chem. Intermed. 2016, 42, 2791-2804. [CrossRef]

20. Chang, C.-C.; Yang, C.-Y.; Lu, C.-H. Preparation and photoluminescence properties of $\mathrm{Sr}_{4} \mathrm{Al}_{14} \mathrm{O}_{25}$ :Eu ${ }^{2+}$ phosphors synthesized via the microemulsion route. J. Mater. Sci. Mater. Electron. 2013, 24, 1458-1462. [CrossRef]

21. Zhu, Y.; Zeng, J.; Li, W.; Xu, L.; Guan, Q.; Liu, Y. Encapsulation of strontium aluminate phosphors to enhance water resistance and luminescence. Appl. Surf. Sci. 2009, 255, 7580-7585. [CrossRef]

22. Lü, X.; Zhong, M.; Shu, W.; Yu, Q.; Xiong, X.; Wang, R. Alumina encapsulated $\mathrm{SrAl}_{2} \mathrm{O}_{4}: \mathrm{Eu}^{2+}$, Dy ${ }^{3+}$ phosphors. Powder Technol. 2007, 177, 83-86. [CrossRef]

23. Tian, S.; Wen, J.; Fan, H.; Chen, Y.; Yan, J.; Zhang, P. Sunlight-activated long persistent luminescent polyurethane incorporated with amino-functionalized $\mathrm{SrAl}_{2} \mathrm{O}_{4}: \mathrm{Eu}^{2+}, \mathrm{Dy}^{3+}$ phosphor. Polym. Int. 2016, 65, 1238-1244. [CrossRef]

24. Oguzlar, S.; Ongun, M.Z.; Keskin, O.Y.; Delice, T.K.; Azem, F.A.; Birlik, I.; Ertekin, K. Investigation of Spectral Interactions between a $\mathrm{SrAl}_{2} \mathrm{O}_{4}: \mathrm{Eu}^{2+}, \mathrm{Dy}^{3+}$ Phosphor and Nano-Scale $\mathrm{TiO}_{2}$. J. Fluoresc. 2020, 30, 839-847. [CrossRef] [PubMed]

25. Khattab, T.A.; Abd El-Aziz, M.; Abdelrahman, M.S.; El-Zawahry, M.; Kamel, S. Development of long-persistent photoluminescent epoxy resin immobilized with europium (II)-doped strontium aluminate. Luminescence 2020, 35, 478-485. [CrossRef] [PubMed]

26. Wan, M.; Jiang, X.; Nie, J.; Cao, Q.; Zheng, W.; Dong, X.; Fan, Z.H.; Zhou, W. Phosphor powders-incorporated polylactic acid polymeric composite used as 3D printing filaments with green luminescence properties. J. Appl. Polym. Sci. 2019, 137, 48644. [CrossRef] 
27. Cheng, L.-X.; Liu, T.; Li, L.; Yang, L.; He, H.-W.; Zhang, J.-C. Self-repairing inorganic phosphors/polymer composite film for restructuring luminescent patterns. Mater. Res. Express 2021, 8, 065302. [CrossRef]

28. De Clercq, D.M.; Chan, S.V.; Hardy, J.; Price, M.B.; Davis, N.J.L.K. Reducing reabsorption in luminescent solar concentrators with a self-assembling polymer matrix. J. Lumin. 2021, 236, 118095. [CrossRef]

29. Poulose, A.M.; Anis, A.; Shaikh, H.; Alhamidi, A.; Siva Kumar, N.; Elnour, A.Y.; Al-Zahrani, S.M. Strontium Aluminate-Based Long Afterglow PP Composites: Phosphorescence, Thermal, and Mechanical Characteristics. Polymers 2021, 13, 1373. [CrossRef]

30. Ye, F.; Dong, S.; Tian, Z.; Yao, S.; Zhou, Z.; Wang, S. Fabrication and characterization of long-persistent luminescence/polymer $\left(\mathrm{Ca}_{2} \mathrm{MgSi}_{2} \mathrm{O}_{7}: \mathrm{Eu}^{2+}, \mathrm{Dy}^{3+} / \mathrm{PLA}\right)$ composite fibers by electrospinning. Opt. Mater. 2015, 45, 64-68. [CrossRef]

31. Khursheed, S.; Kumar, V.; Singh, V.K.; Sharma, J.; Swart, H. Optical properties of $\mathrm{Sr}_{3} \mathrm{~B}_{2} \mathrm{O}_{6}$ : $\mathrm{Dy}^{3+} /$ PMMA polymer nanocomposites. Phys. B Condens. Matter 2018, 535, 184-188. [CrossRef]

32. George, G.; Luo, Z. A Review on Electrospun Luminescent Nanofibers: Photoluminescence Characteristics and Potential Applications. Curr. Nanosci. 2020, 16, 321-362. [CrossRef]

33. Bem, D.; Swart, H.; Luyt, A.; Coetzee, E.; Dejene, F. Properties of green $\mathrm{SrAl}_{2} \mathrm{O}_{4}$ phosphor in LDPE and PMMA polymers. J. Appl. Polym. Sci. 2010, 117, 2635-2640. [CrossRef]

34. Ni, Z.; Fan, T.; Bai, S.; Zhou, S.; Lv, Y.; Ni, Y.; Xu, B. Effect of the Concentration of $\mathrm{SrAl}_{2} \mathrm{O}_{4}$ : $\mathrm{Eu}^{2+}$ and Dy ${ }^{3+}(\mathrm{SAO})$ on Characteristics and Properties of Environment Friendly Long-Persistent Luminescence Composites from Polylactic Acid and SAO. Scanning 2021, 2021, 6337768. [CrossRef] [PubMed]

35. Włochowicz, A.; Eder, M. Distribution of lamella thicknesses in isothermally crystallized polypropylene and polyethylene by differential scanning calorimetry. Polymer 1984, 25, 1268-1270. [CrossRef]

36. Ouchiar, S.; Stoclet, G.G.; Cabaret, C.; Gloaguen, V. Influence of the filler nature on the crystalline structure of polylactide-based nanocomposites: New insights into the nucleating effect. Macromolecules 2016, 49, 2782-2790. [CrossRef]

37. Xu, J.; Tanabe, S. Persistent luminescence instead of phosphorescence: History, mechanism, and perspective. J. Lumin. 2019, 205, 581-620. [CrossRef]

38. Clabau, F.; Rocquefelte, X.; Jobic, S.; Deniard, P.; Whangbo, M.-H.; Garcia, A.; Le Mercier, T. Mechanism of phosphorescence appropriate for the long-lasting phosphors $\mathrm{Eu}^{2+}$-doped $\mathrm{SrAl}_{2} \mathrm{O}_{4}$ with codopants $\mathrm{Dy}^{3+}$ and $\mathrm{B}^{3+}$. Chem. Mater. 2005, 17, 3904-3912. [CrossRef]

39. Dorenbos, P. Mechanism of persistent luminescence in $\mathrm{Eu}^{2+}$ and $\mathrm{Dy}^{3+}$ codoped aluminate and silicate compounds. J. Electrochem. Soc. 2005, 152, H107-H110. [CrossRef]

40. Lephoto, M.A.; Ntwaeaborwa, O.M.; Pitale, S.S.; Swart, H.C.; Botha, J.R.; Mothudi, B.M. Synthesis and characterization of $\mathrm{BaAl}_{2} \mathrm{O}_{4}: \mathrm{Eu}^{2+}$ co-doped with different rare earth ions. Phys. B Condens. Matter 2012, 407, 1603-1606. [CrossRef]

41. Kim, S.; Lee, Y.; Kim, C.; Choi, S. Analysis of Mechanical Property Degradation of Outdoor Weather-Exposed Polymers. Polymers 2022, 14, 357. [CrossRef] 